\title{
Low velocity impact analysis of composite sandwich shells using higher-order shear deformation theories
}

\author{
DIPAK K MAITI and P K SINHA \\ Department of Aerospace Engineering, Indian Institute of Technology, \\ Kharagpur 721 302, India \\ e-mail: pksinha@aero.iitkgp.ernet.in
}

\begin{abstract}
In the present investigation, higher-order and conventional firstorder shear deformation theories are used to study the impact response of composite sandwich shells. The formulation is based on Donnell's shallow shell theory. Nine-noded Lagrangian elements are used for the finite element formulation. A modified Hertzian contact law is used to calculate the contact force. The results obtained from the present investigation are found to compare well with those existing in the open literature. The numerical results are presented to study the changes in the impact response due to the increase of core depth from zero to some specified value and the changes in core stiffness for a particular core depth.
\end{abstract}

Keywords. Composite sandwich shell; contact force; finite element analysis; Hertzian contact; low velocity impact; transverse shear stress.

\section{Introduction}

Composites and composite sandwiches, due to their high specific strengths and stiffnesses and several other attributes, are normally favoured in the design of several aircraft structural components. Some of these structural components are likely to experience low velocity impact during their manufacture, storage or service life. The impact due to a tool drop and that due to hits by flying debris, birds, hail stones etc. are common examples of low velocity impact. The understanding of dynamic response of composite and sandwich structures subjected to low velocity impact is, therefore, necessary for design and assessment of damage resistance.

The design/analysis techniques for the response of composite materials and structures under static loads and simpler forms of dynamic loads are well established. But not much effort has been directed to study the impact response of laminated composite structures and composite sandwiches. It is only in recent years that there has been a growing interest to investigate impact related problems, especially those involving composite materials. A significant contribution to the impact behaviour of composite laminates was made by Yang \& Sun $(1981,1982)$ and Tan \& Sun (1985). Based on an experimental investigation, they proposed empirical relations for the contact force due to loading, unloading and 
reloading during the impact process. Tan \& Sun (1985) also analysed the impact response of laminated composite plates using the finite element method (FEM) and modified contact law for composite laminates. The transient response of laminated composite structures under transverse impact was also studied by Cairns \& Lagace (1989) and Wu \& Chang (1989) using FEM. Wu \& Springer (1988) employed a three-dimensional transient FEM using 8-noded brick elements to determine the size and location of delaminations in the laminated composite plates subjected to a non-penetrating impact. Maiti \& Sinha (1995a, b) studied the impact behaviour of thick laminated composite beams and plates using FEM based on higher-order shear deformation theories.

The low velocity impact response of composite shells is of paramount importance in view of the extensive use of composites in aerospace applications. But the information available in the open literature on the subject matter is very limited. A double Fourier series expansion method to study the impact response of simply supported cylindrical shells was used by Christoforou \& Swanson (1990). The impact induced fracture in laminated plates and cylindrical shells was studied by Lin \& Lee (1990) using an experimental technique as well as FEM. The impact response of composite cylinders using a mixed finite element method and Tsai-Wu failure criterion was investigated by Bachrach \& Hansen (1989). In a recent investigation (Maiti \& Sinha 1995c), we employed FEM to study the impact behaviour of doubly curved laminated composite shells.

The sandwich constructions are stiffness and weight effective. Therefore, they are increasingly used in the aerospace industry. The effects of face lay-up sequence and core density of a sandwich plate due to impact were investigated by Kim \& Jun (1992) and they observed that small relative orientation between adjacent plies and the higher density core are desirable in sandwich plates to reduce impact delamination. The low-velocity impact response of foam-core composites with fibre glass/epoxy face sheet was treated by a combination of computational and experimental methods by Nemes \& Simmonds (1992). They used four-noded constant strain quadrilateral elements and linear elastic constitutive models for the face sheets and a phenomenological constitutive relation for the epoxy bonded layer along with the foam core. However, the literature available on the impact response of composite sandwiches is so meagre that no meaningful conclusion can be drawn about the actual behaviour. Moreover, polymer composite faces, in general, and common core materials, in particular, exhibit low transverse shear modulus and strength properties. This may require the use of higher-order shear deformation theories for accurate estimation of transverse shear stresses and for subsequent prediction of interlaminar failure and identification of damage zones.

In the present investigation the higher-order shear deformation theories (e.g., HST9, HST11, HST12) as well as the conventional first-order shear deformation theory (FST) are employed to develop a finite element method to investigate the impact behaviour of doubly-curved composite sandwich shells. The finite element method incorporates the nine-noded quadrilateral elements of the Lagrange family. Shell behaviour is based on Donnell's shallow shell theory. The results depict how the impact response changes due to the increase of core thickness from zero to some specified values and the change in core stiffnesses for a particular core depth. The present FEM also provides a means to make a comparative assessment of various forms of shear deformation theories for applications in the present case. 


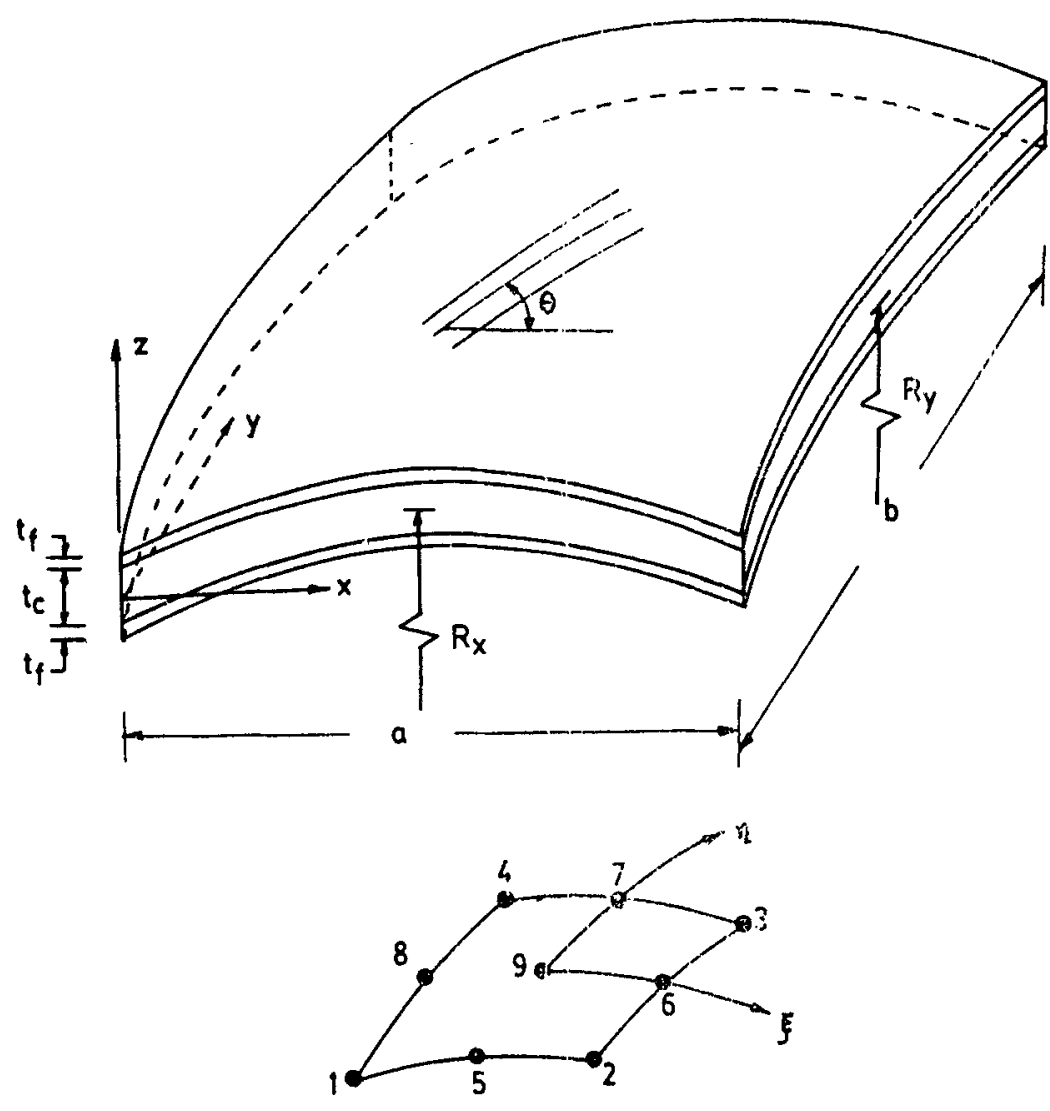

\section{9-noded isoparametric element}

Figure 1. Composite sandwich shell and 9-noded isoparametric element configuration.

\section{Formulation}

A doubly-curved sandwich composite shell configuration and a schematic view of a ninenoded quadrilateral isoparametric element are shown in figure 1 . In the present sandwich construction, a core of thick low density material is bonded to two face sheets of composite laminates having arbitrary lamina thickness, materials and fibre orientations. The displacement components at any point $(x, y, z)$ along three perpendicular directions are expressed as

(i) First-order shear deformation theory (FST):

$$
\begin{aligned}
u(x, y, z, t) & =u_{0}(x, y, t)+z \theta_{x}(x, y, t) \\
v(x, y, z, t) & =v_{0}(x, y, t)+z \theta_{y}(x, y, t) \\
w(x, y, z, t) & =w_{0}(x, y, t)
\end{aligned}
$$


Higher-order shear deformation theories (HST):

(ii) Nine-degrees of freedom system (HST9),

$$
\begin{aligned}
u(x, y, z, t) & =u_{0}(x, y, t)+z \theta_{x}(x, y, t)+z^{2} \bar{u}_{0}(x, y, t)+z^{3} \bar{\theta}_{x}(x, y, t), \\
v(x, y, z, t) & =v_{0}(x, y, t)+z \theta_{y}(x, y, t)+z^{2} \bar{v}_{0}(x, y, t)+z^{3} \bar{\theta}_{y}(x, y, t), \\
w(x, y, z, t) & =w_{0}(x, y, t)
\end{aligned}
$$

(iii) Eleven-degrees of freedom system (HST11)

$$
\begin{aligned}
u(x, y, z, t) & =u_{0}(x, y, t)+z \theta_{x}(x, y, t)+z^{2} \bar{u}_{0}(x, y, t)+z^{3} \bar{\theta}_{x}(x, y, t), \\
v(x, y, z, t) & =v_{0}(x, y, t)+z \theta_{y}(x, y, t)+z^{2} \bar{v}_{0}(x, y, t)+z^{3} \bar{\theta}_{y}(x, y, t) \\
w(x, y, z, t) & =w_{0}(x, y, t)+z \theta_{z}(x, y, t)+z^{2} \bar{w}_{0}(x, y, t)
\end{aligned}
$$

(iv) Twelve-degrees of freedom system (HST12)

$$
\begin{aligned}
u(x, y, z, t) & =u_{0}(x, y, t)+z \theta_{x}(x, y, t)+z^{2} \bar{u}_{0}(x, y, t)+z^{3} \bar{\theta}_{x}(x, y, t) \\
v(x, y, z, t) & =v_{0}(x, y, t)+z \theta_{y}(x, y, t)+z^{2} \bar{v}_{0}(x, y, t)+z^{3} \bar{\theta}_{y}(x, y, t) \\
w(x, y, z, t) & =w_{0}(x, y, t)+z \theta_{z}(x, y, t)+z^{2} \bar{w}_{0}(x, y, t)+z^{3} \bar{\theta}_{z}(x, y, t)
\end{aligned}
$$

where $u_{0}, v_{0}, w_{0}$ and $\theta_{x}, \theta_{y}, \theta_{z}$, are midplane displacements and rotations and where $\bar{u}_{0}$, $\bar{v}_{0}, \bar{w}_{0}$ and $\bar{\theta}_{x}, \bar{\theta}_{y}, \bar{\theta}_{z}$ are corresponding higher-order terms in Taylor's series expansion.

Typical strain-displacement relations for HST12 based on Donnell's shallow shell theory are expressed as

$$
\left\{\begin{array}{c}
\epsilon_{x x} \\
\epsilon_{y y} \\
\epsilon_{z z} \\
\gamma_{x y} \\
\gamma_{y z} \\
\gamma_{x z}
\end{array}\right\}=\left\{\begin{array}{c}
\epsilon_{x x}^{0} \\
\epsilon_{y y}^{0} \\
\epsilon_{z z}^{0} \\
\gamma_{x y}^{0} \\
\gamma_{y z}^{0} \\
\gamma_{x z}^{0}
\end{array}\right\}+z\left\{\begin{array}{l}
k_{x x} \\
k_{y y} \\
k_{z z} \\
k_{x y} \\
k_{y z} \\
k_{x z}
\end{array}\right\}+z^{2}\left\{\begin{array}{l}
\bar{\epsilon}_{x x}^{0} \\
\bar{\epsilon}_{y y}^{0} \\
\bar{\epsilon}_{z z}^{0} \\
\bar{\gamma}_{x y}^{0} \\
\bar{\gamma}_{y z}^{0} \\
\bar{\gamma}_{x z}^{0}
\end{array}\right\}+z^{3}\left\{\begin{array}{c}
\bar{k}_{x x} \\
\bar{k}_{y y} \\
0 \\
\bar{k}_{x y} \\
\bar{k}_{y z} \\
\bar{k}_{x z}
\end{array}\right\}
$$

where $\epsilon_{x x}, \epsilon_{y y}, \epsilon_{z z}$ etc. are engineering strains and $\epsilon_{x x}^{0}, \epsilon_{y y}^{0}, \epsilon_{z z}^{0}$ etc. are generalised strain components and are expressed in terms of displacements $\left(u_{0}, v_{0}, w_{0}, \theta_{x}, \theta_{y}, \theta_{z}\right.$ etc. as shown in (A1) in the appendix. Note that the term $\bar{k}_{z z}$ does not exist in the present case.

Nine-noded Lagrangian quadratic elements are used for the finite element formulation. The shape functions for a nine-noded quadrilateral isoparametric elements are

$$
\begin{aligned}
& N_{i}=(1 / 4)\left(1+\xi \xi_{i}\right)\left(1+\eta \eta_{i}\right) \xi \xi_{i} \eta \eta_{i}, \quad i=1,2,3,4, \\
& N_{i}=(1 / 2)\left(1-\xi^{2}\right)\left(1+\eta \eta_{i}\right) \eta \eta_{i}, \quad i=5,7, \\
& N_{i}=(1 / 2)\left(1+\xi \xi_{i}\right)\left(1-\eta^{2}\right) \xi \xi_{i}, \quad i=6,8, \\
& N_{9}=\left(1-\xi^{2}\right)\left(1-\eta^{2}\right) .
\end{aligned}
$$


The displacements $\left(u_{0}, v_{0}, w_{0}, \theta_{x}, \theta_{y}, \theta_{z}\right.$ etc.) at a point within the element in terms of interpolation functions and nodal degrees of freedom are expressed as follows

$$
\begin{array}{lll}
u_{0}=\sum_{i=1}^{9} N_{i} u_{0 i}, & v_{0}=\sum_{i=1}^{9} N_{i} v_{0 i}, & w_{0}=\sum_{i=1}^{9} N_{i} w_{0 i}, \\
\theta_{x}=\sum_{i=1}^{9} N_{i} \theta_{x i}, & \theta_{y}=\sum_{i=1}^{9} N_{i} \theta_{y i}, & \theta_{z}=\sum_{i=1}^{9} N_{i} \theta_{z i}, \\
\bar{u}_{0}=\sum_{i=1}^{9} N_{i} \bar{u}_{0 i}, & \bar{v}_{0}=\sum_{i=1}^{9} N_{i} \bar{v}_{0 i}, & \bar{w}_{0}=\sum_{i=1}^{9} N_{i} \bar{w}_{0 i}, \\
\bar{\theta}_{x}=\sum_{i=1}^{9} N_{i} \bar{\theta}_{x i}, & \bar{\theta}_{y}=\sum_{i=1}^{9} N_{i} \bar{\theta}_{y i}, & \bar{\theta}_{z}=\sum_{i=1}^{9} N_{i} \bar{\theta}_{z i},
\end{array}
$$

Combining (5) and (7) in conjunction with (A1), the strain-displacement relations are expressed as,

$$
\{\epsilon\}=[B]\left\{u_{e}\right\},
$$

where $[B]$ is the strain-displacement matrix and is presented in the appendix. $\left\{u_{e}\right\}$ is the element displacement vector.

The dynamic equilibrium equation for a finite element is derived using Hamilton's principle, as

$$
\delta \int_{t_{1}}^{t_{2}} L_{e}=0
$$

where $L_{e}$ is the Lagrange energy function.

Substituting energy expressions and performing the integration, the expression for the dynamic equilibrium becomes,

$$
\left[M_{e}\right]\left\{\ddot{u}_{e}\right\}+\left[K_{e}\right]\left\{u_{e}\right\}=\left\{F_{e}\right\},
$$

where the element mass matrix $\left[M_{e}\right]$ can be expressed as

$$
\left[M_{e}\right]=\iint[N]^{T}[\rho][N] \mathrm{d} x \mathrm{~d} y
$$

where $[N]$ is the shape function matrix and $[\rho]$ is the inertia matrix as given in (7) by Maiti \& Sinha (1994).

Similarly, the element stiffness matrix $\left[K_{e}\right]$ is given as

$$
\left[K_{e}\right]=\iint[B]^{T}[D][B] \mathrm{d} x \mathrm{~d} y
$$

where $[B]$ is the strain-displacement matrix as listed in the appendix, and $[D]$ is the rigidity matrix as reported by Maiti \& Sinha (1994) and is based on three-dimensional anisotropic constitutive relations.

After assembling all the element mass and stiffness matrices and the force vector with respect to the common global coordinates, the resulting equilibrium equation becomes 
(i) Forced vibration equation

$$
[M]\{\ddot{u}\}+[K]\{u\}=\{F\} .
$$

(ii) Free-vibration equation

$$
[M]\{\ddot{u}\}+[K]\{u\}=0 .
$$

(iii) Bending

$$
[K]\{u\}=\{F\},
$$

where $[M]$ and $[K]$ are global mass and stiffness matrices and $\{u\},\{\ddot{u}\}$ and $\{F\}$ are global displacement, acceleration and force vectors respectively. For the impact problem, $\{F\}$ is given as

$$
\{F\}=\left[000 \ldots F_{c} \ldots 000\right]^{T} .
$$

Note that $F_{c}$ is the contact force corresponding to the contact point.

The dynamic equilibrium of the impactor can be expressed as follows:

$$
m_{i} \ddot{w}_{i}+F_{c}=0
$$

where $m_{i}$ and $\ddot{w}_{i}$ are impactor mass and acceleration respectively.

Equations (13)-(15) govern the structural response, while (17) defines the impactor motion. It should be noted that the contact force vector $\{F\}$ must be calculated before the target response can be analysed. The solution of (13) and (17) is achieved employing Newmark's time integration scheme. Equations (14) and (15) are solved by the subspace iteration method and the Gauss elimination method respectively.

\section{Contact laws}

During loading the contact force can be calculated using the modified Hertzian contact law as follows,

$$
F_{c}=n \alpha^{3 / 2}
$$

where $\alpha$ is the local indentation and $n$ is the modified contact stiffness for composite materials proposed by Yang \& Sun (1982) as

$$
\begin{aligned}
& n=\frac{4}{3} \sqrt{R}_{i} \frac{1}{\left(1-v_{i}^{2}\right) / E_{i}+1 / E_{33}}, \text { for plate, } \\
& n=\frac{4}{3}\left[\frac{1}{1 / R_{i}+1 / 2 R_{s}}\right]^{1 / 2} \frac{1}{\left(1-v_{i}^{2}\right) / E_{i}+1 / E_{33}}, \text { for cylindrical shell, } \\
& n=\frac{4}{3}\left[\frac{1}{1 / R_{i}+1 / R_{s}}\right]^{1 / 2} \frac{1}{\left(1-v_{i}^{2}\right) / E_{i}+1 / E_{33}}, \text { for spherical shell, }
\end{aligned}
$$


where $R_{i}, E_{i}$ and $v_{i}$ are the radius, modulus of elasticity and Poisson's ratio of the impactor and $R_{S}$ and $E_{33}$ are radius and transverse modulus of elasticity of composite cylindrical and spherical shell targets.

Upon unloading, the contact force is simulated by the following relation,

$$
F_{c}=F_{m}\left[\frac{\alpha-\alpha_{0}}{\alpha_{m}-\alpha_{0}}\right]^{2.5},
$$

and for reloading the indentation law is modified as,

$$
F_{c}=F_{m}\left[\frac{\alpha-\alpha_{0}}{\alpha_{m}-\alpha_{0}}\right]^{1.5},
$$

where $F_{m}$ is the maximum contact force just before unloading, $\alpha_{m}$ is the maximum local indentation during this loading/unloading process. The permanent indentation is determined from the following expressions

$$
\begin{aligned}
& \alpha_{0}=0, \quad \text { when } \alpha_{m}<\alpha_{c r}, \\
& \alpha_{0}=\alpha_{m}\left[1-\left(\alpha_{c r} / \alpha_{m}\right)\right]^{2 / 5}, \quad \text { when } \alpha_{m} \geq \alpha_{c r},
\end{aligned}
$$

$\alpha_{c r}$ is the critical indentation beyond which permanent indentation will occur and is approximately equal to $8.0264 \times 10^{-5} \mathrm{~m}(0.00316 \mathrm{in}$.) for a graphite-epoxy composite face.

\section{Numerical results and discussion}

Based on the above finite element procedure, computer programs are developed to study the impact behaviour of laminated sandwich shells. The computer programs are coded with the help of Fortran-77 language and the analysis is carried using a 486 (Oasys) system under Unix environment. For the present first-order shear deformation theory, a shear correction factor of $5 / 6$ is used to modify the shear energy and no shear correction factor is used for the higher-order shear deformation theories. The following boundary conditions are used:

Simply support:

$$
\begin{array}{ll}
v_{0}=w_{0}=\theta_{y}=\theta_{z}=\bar{v}_{0}=\bar{w}_{0}=\bar{\theta}_{y}=\bar{\theta}_{z}=0, & \text { at } x=0, a, \\
u_{0}=w_{0}=\theta_{x}=\theta_{z}=\bar{u}_{0}=\bar{w}_{0}=\bar{\theta}_{x}=\bar{\theta}_{z}=0, & \text { at } y=0, b .
\end{array}
$$

Clamped-clamped support:

$$
\begin{gathered}
u_{0}=v_{0}=w_{0}=\theta_{x}=\theta_{y}=\theta_{z}=\bar{u}_{0}=\bar{v}_{0}=\bar{w}_{0}=\bar{\theta}_{x}=\bar{\theta}_{y}=\bar{\theta}_{z}=0 \\
\text { at } x=0, \text { a and at } y=0, b
\end{gathered}
$$

Clamped-free support:

$$
\begin{gathered}
u_{0}=v_{0}=w_{0}=\theta_{x}=\theta_{y}=\theta_{z}=\bar{u}_{0}=\bar{v}_{0}=\bar{w}_{0}=\bar{\theta}_{x}=\bar{\theta}_{y}=\bar{\theta}_{z}=0 \\
\text { at } x=0 \text { and } u_{0}, v_{0}, w_{0}, \text { etc. are not specified at other edges. }
\end{gathered}
$$


Table 1. Non-dimensionalised central deflections and stresses for a simply supported square sandwich plate subjected to sinusoidal load ( $4 \times 4$ mesh, quarter plate).

\begin{tabular}{lccccccc}
\hline Method & $\bar{w}$ & $\bar{\sigma}_{x x}(1)$ & $\bar{\sigma}_{x x}(2)$ & $\bar{\sigma}_{y y}$ & $\bar{\tau}_{x y}$ & $\bar{\tau}_{y z}$ & $\bar{\tau}_{x z}$ \\
\hline$S=100$ & & & & & & & \\
FST & 0.8851 & \pm 1.1242 & \pm 0.8994 & \pm 0.0559 & 0.0445 & 0.0258 & 0.3001 \\
HST9 & 0.8910 & \pm 1.1246 & \pm 0.8969 & \pm 0.0562 & 0.0447 & 0.0265 & 0.3069 \\
HST11 & 0.8867 & \pm 1.1225 & \pm 0.8952 & \pm 0.0583 & 0.0445 & 0.0270 & 0.3064 \\
HST12 & 0.8867 & \pm 1.1225 & \pm 0.8952 & \pm 0.0583 & 0.0445 & 0.0270 & 0.3064 \\
Exact & - & \pm 1.0980 & \pm 0.8750 & \pm 0.0550 & 0.0437 & 0.0297 & 0.3240 \\
$S=50$ & & & & & & & \\
FST & 0.9062 & \pm 1.225 & \pm 0.8980 & \pm 0.0568 & 0.0449 & 0.0266 & 0.3046 \\
HST9 & 0.9293 & \pm 1.1267 & \pm 0.8907 & \pm 0.0580 & 0.0456 & 0.0270 & 0.3040 \\
HST11 & 0.9253 & \pm 1.1246 & \pm 0.8890 & \pm 0.0601 & 0.0454 & 0.0275 & 0.3034 \\
HST12 & 0.9253 & \pm 1.1246 & \pm 0.8890 & \pm 0.0601 & 0.0454 & 0.0275 & 0.3034 \\
Exact & - & \pm 1.099 & \pm 0.8670 & \pm 0.0569 & 0.0446 & 0.0306 & 0.3230 \\
$S=20$ & & & & & & & \\
FST & 1.0524 & \pm 1.1105 & \pm 0.8884 & \pm 0.0628 & 0.0477 & 0.0288 & 0.3018 \\
HST9 & 1.1944 & \pm 1.1372 & \pm 0.8440 & \pm 0.0699 & 0.0516 & 0.0313 & 0.2984 \\
HST11 & 1.1901 & \pm 1.1352 & \pm 0.8423 & \pm 0.0722 & 0.0514 & 0.0318 & 0.2978 \\
HST12 & 1.1901 & \pm 1.1352 & \pm 0.8423 & \pm 0.0722 & 0.0514 & 0.0318 & 0.2978 \\
Exact & - & \pm 1.1100 & \pm 0.8100 & \pm 0.0700 & 0.0511 & 0.0361 & 0.3170 \\
$S=10$ & & & & & & & \\
FST & 1.5605 & \pm 1.0720 & \pm 0.8576 & \pm 0.0818 & 0.0565 & 0.0361 & 0.2940 \\
HST9 & 2.0849 & \pm 1.1784 & \pm 0.6928 & \pm 0.1068 & 0.0705 & 0.0446 & 0.2821 \\
HST11 & 2.0807 & \pm 1.1765 & \pm 0.6913 & \pm 0.1094 & 0.0701 & 0.0450 & 0.2815 \\
HST12 & 2.0807 & \pm 1.1765 & \pm 0.6913 & \pm 0.1095 & 0.0701 & 0.0450 & 0.2815 \\
Exact & - & \pm 1.1520 & \pm 0.629 & \pm 0.1099 & 0.0717 & 0.0527 & 0.3000 \\
\hline Exac & & & & & & &
\end{tabular}

Exact values correspond to those of Pagano (1970)

$\bar{w}=100 E_{22 f} w / q_{0} h S^{4},\left(\bar{\sigma}_{x x}, \bar{\sigma}_{y y}, \bar{\tau}_{x y}\right)=1 / q_{0} S^{2}\left(\sigma_{x x}, \sigma_{y y}, \tau_{x y}\right),\left(\bar{\tau}_{x z}, \bar{\tau}_{y z}\right)=1 / q_{0} S\left(\tau_{x z}, \tau_{y z}\right)$, $S=a / h \sigma_{x x}(1)$ at $(a / 2, b / 2, \pm h / 2), \sigma_{x x}(2)$ at $(a / 2, b / 2, \pm 0.4 h), \sigma_{y y}$ at $(a / 2, b / 2, \pm h / 2)$, $\tau_{x y}$ at $(0,0, \pm h / 2), \tau_{y z}$ at $(a / 2,0, \pm h / 2), \tau_{x z}$ at $(0, b / 2,0)$,

\subsection{Comparison of results}

To establish the present finite element formulation, bending and free vibration results are compared with those existing in the literature. Non-dimensionalised central deflections $(\bar{w})$ and stresses $\left(\bar{\sigma}_{x x}, \bar{\sigma}_{y y}, \bar{\tau}_{x y}, \bar{\tau}_{y z}, \bar{\tau}_{x z}\right)$, for a simply supported sandwich plate subjected to sinusoidal surface loading, are presented in table 1 . The material properties and lay-ups are used as assumed by Pagano (1970). It is observed that the results agree well for thin sandwich plates but differences are noted with the increase in $a / h$ ratio. In comparison to the first-order shear deformation theory, the higher-order shear deformation theories 
Table 2. Natural frequency $(\mathrm{Hz})$ for a simply supported sandwich plate.

\begin{tabular}{lccccccc}
\hline $\begin{array}{l}\text { Mode } \\
m, n\end{array}$ & $\begin{array}{c}\text { Raville- } \\
\text { Ueng } \\
\text { Exp. }\end{array}$ & $\begin{array}{c}\text { Raville- } \\
\text { Ueng } \\
\text { Theory }\end{array}$ & $\begin{array}{c}\text { Khatua- } \\
\text { Cheung } \\
\text { FEM }\end{array}$ & Fresent & Present & Present & Present \\
\hline 1,1 & - & 23 & 23 & 23.289 & 23.327 & 23.326 & 23.326 \\
2,1 & 45 & 45 & 45 & 44.178 & 44.303 & 44.307 & 44.307 \\
1,2 & 69 & 71 & 71 & 69.689 & 70.056 & 70.061 & 70.061 \\
3,1 & 78 & 80 & 82 & 79.918 & 80.167 & 80.178 & 80.178 \\
2,2 & 92 & 91 & 92 & 89.059 & 89.651 & 89.676 & 89.676 \\
3,2 & 129 & 126 & 128 & 123.499 & 124.374 & 124.401 & 124.401 \\
4,1 & 133 & 129 & 136 & 128.657 & 129.271 & 129.356 & 129.356 \\
1,3 & 152 & 146 & 150 & 143.280 & 144.754 & 144.780 & 144.780 \\
\hline
\end{tabular}

yield results closer to the exact solution of Pagano (1970). The natural frequencies $(\mathrm{Hz})$ for a composite sandwich plate using the present FEM analysis (table 2) are also found to compare well with those of Khatua \& Cheung (1973) and Raville \& Ueng (1967).

The impact response is analysed using both higher-order and first-order shear deformation theories for the target structure (simply supported isotropic plate) of Goldsmith (1960). The results are shown in figure 2 . The contact force variation, impactor displacement $\left(w_{i}\right)$, target point displacement $(w)$ and velocity profile $\left(v_{i}\right)$ of impactor are plotted. From figure 2 it is observed that the contact force, impactor displacement $\left(w_{i}\right)$ and velocity profile match well but some discrepancies are observed in the case of target point displacement response. Figures 3 and 4 show the contact force variation and displacement response of target point for a laminated composite plate centrally impacted by a spherical steel impactor with an initial velocity of $3 \mathrm{~m} / \mathrm{s}$. Material properties are as those used by Sun \& Chen (1985). The results are plotted with those of Sun \& Chen (1985) and Cairns \& Lagace (1989). Here also differences are observed but the nature of variation is the same. This difference specially in the case of displacement response (figure 4), though not significant, may be attributed due to the variation in the contact stiffness. It is also to be noted that only HST11 results are plotted in figures $2-4$ because such results obtained using different shear deformation theories are very close to each other.

\subsection{Material and geometric data for other results}

Numerical results are obtained to study the impact response of laminated sandwich shells. The lamina properties used, unless otherwise stated, are as follows:

T300/934 graphite-epoxy composites (face material):

$$
\begin{aligned}
& E_{11}=141.2 \mathrm{GPa}, E_{22}=E_{33}=9.72 \mathrm{GPa}, G_{12}=G_{13}=5.53 \mathrm{GPa}, \\
& G_{23}=3.74 \mathrm{GPa}, v_{12}=0.30, v_{23}=0.30, \rho=1536 \mathrm{~kg} / \mathrm{m}^{3}, \\
& a=b=0.20 \mathrm{~m}
\end{aligned}
$$




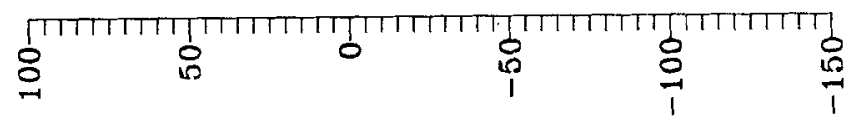

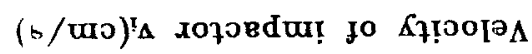
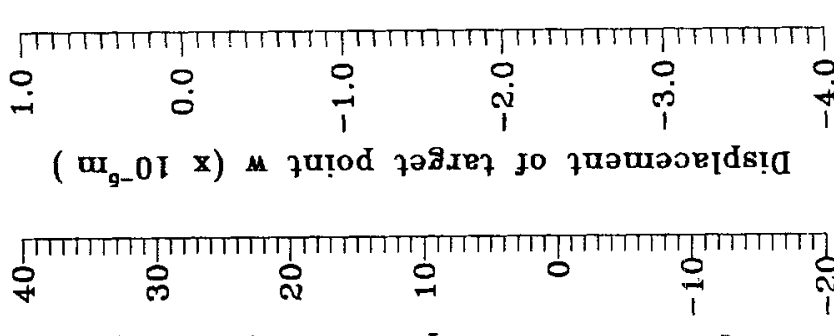

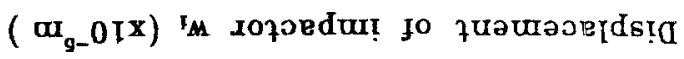

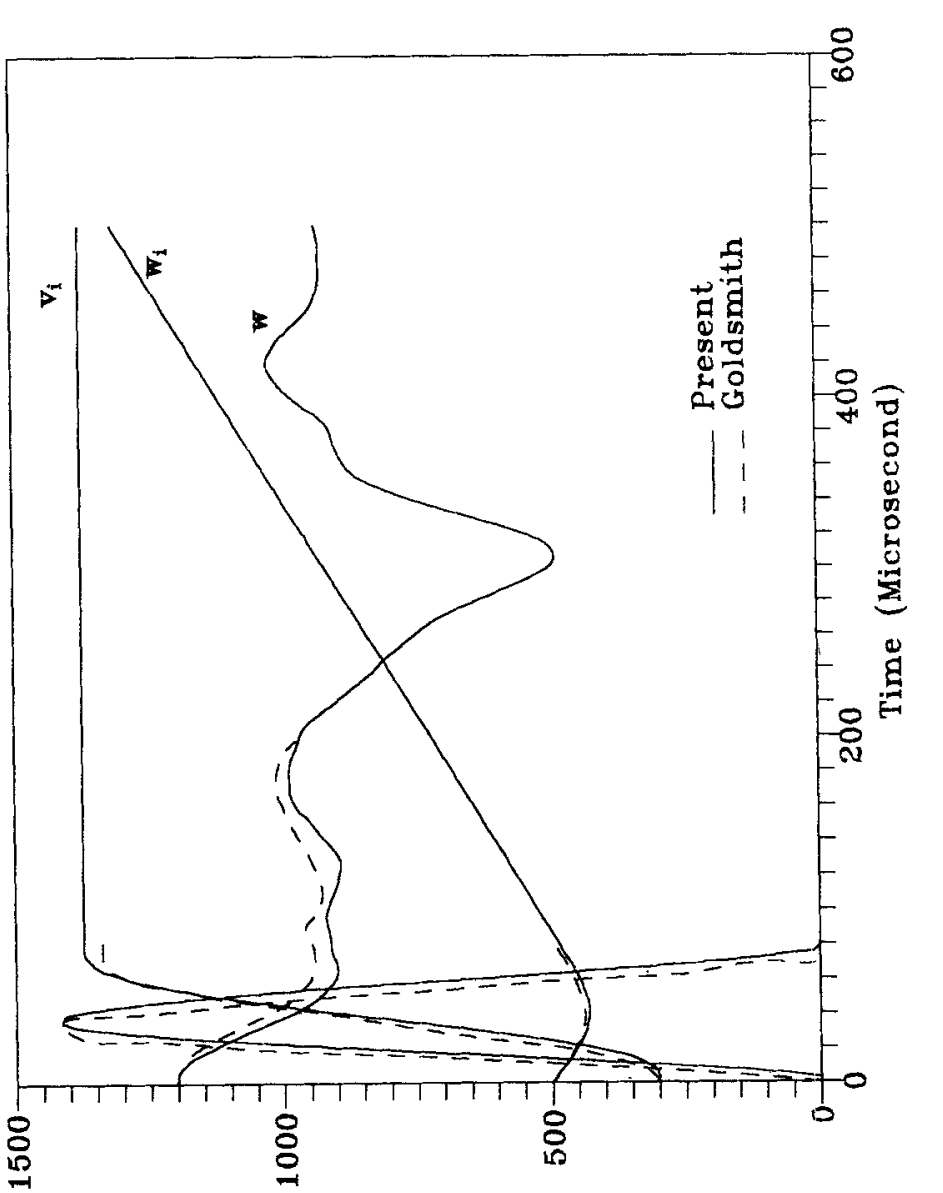

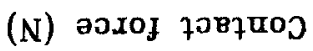




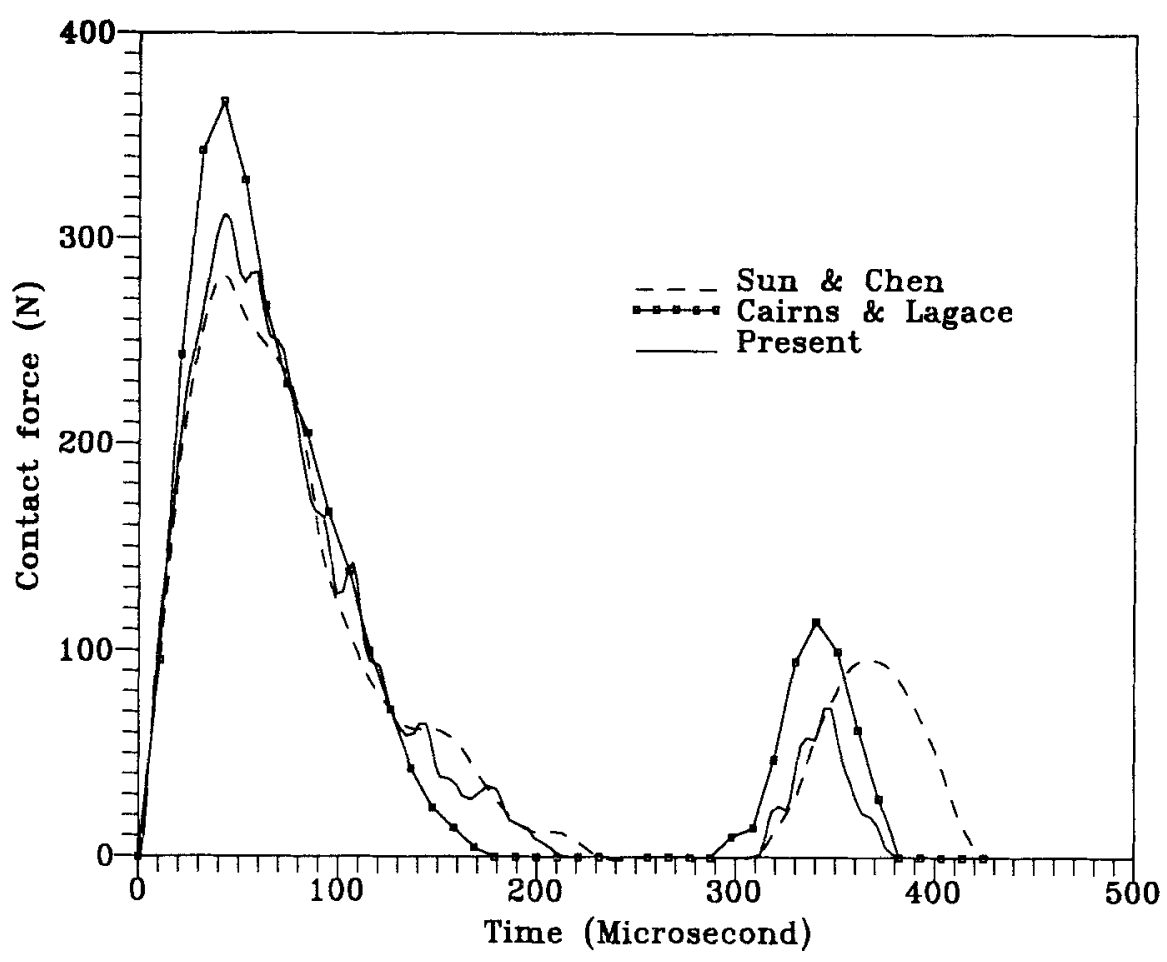

Figure 3. Contact force variation for a simply supported square composite plate.

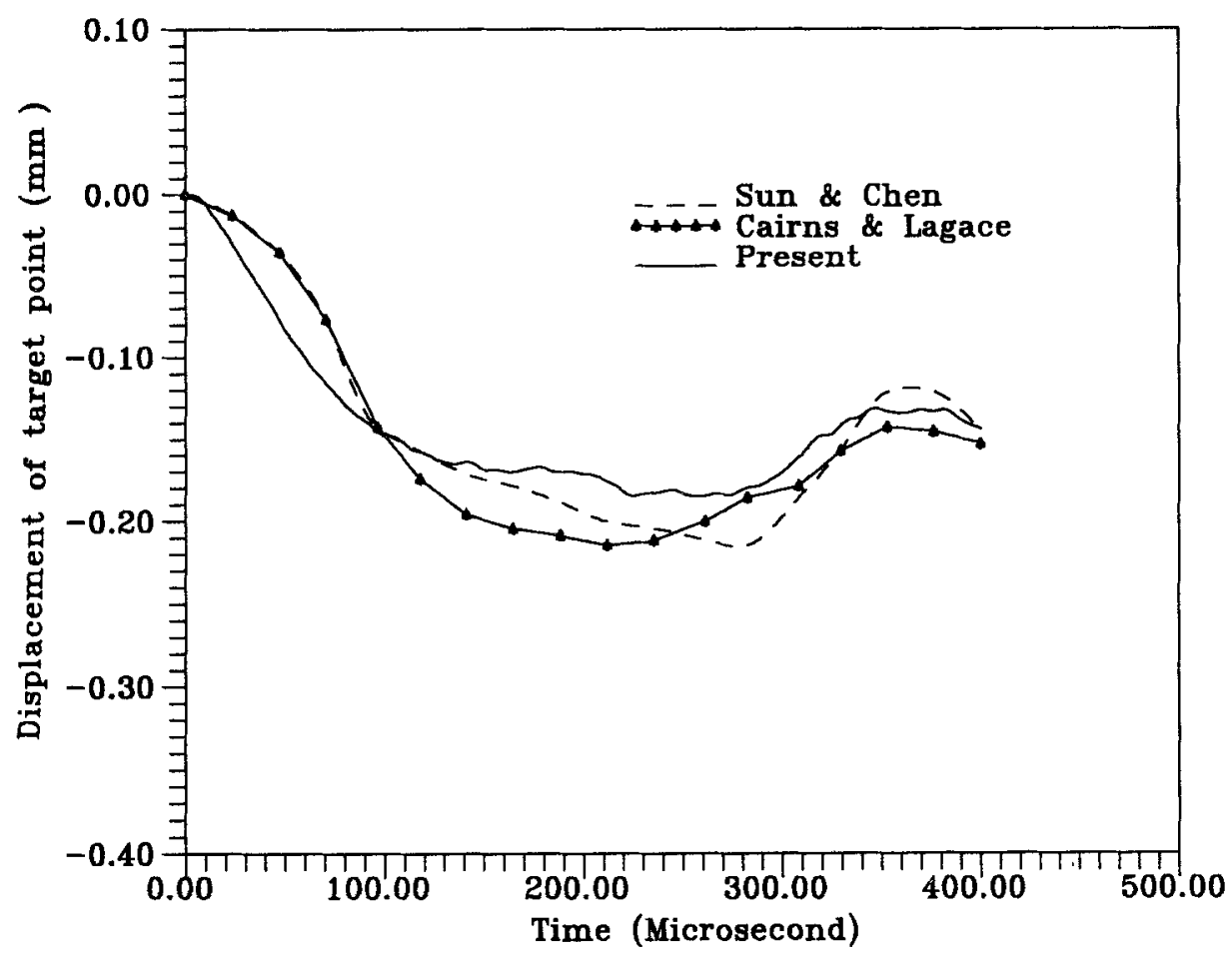

Figure 4. Target point displacement response of a simply supported square composite plate. 
Core materials:

Case 1

$$
\begin{aligned}
& E_{22 f} / E_{11 c}=E_{22 f} / E_{22 c}=10, \quad E_{22 c} / E_{33 c}=10 \\
& E_{22 f} / G_{12 c}=E_{22 f} / G_{13 c}=E_{22 f} / G_{23 c}=10, \\
& \nu_{12 c}=0.35, \quad \nu_{23 c}=0.035, \quad \rho=121.874 \mathrm{~kg} / \mathrm{m}^{3},
\end{aligned}
$$

Case 2

$$
\begin{aligned}
& E_{22 f} / E_{11 c}=E_{22 f} / E_{22 c}=10, \quad E_{22 c} / E_{33 c}=10 \\
& v_{12 c}=0.35, \quad v_{23 c}=0.035, \quad \rho=121.874 \mathrm{~kg} / \mathrm{m}^{3} \\
& E_{22 f} / G_{12 c}=E_{22 f} / G_{13 c}=E_{22 f} / G_{23 c}=4,10,20 .
\end{aligned}
$$

Case 3

$$
\begin{aligned}
& E_{11 c}=E_{22 c}=G_{12 c}=0, \quad \nu_{12 c}=v_{23 c}=0, \\
& E_{22 f} / G_{13 c}=E_{22 f} / G_{23 c}=10 \rho=121.874 \mathrm{~kg} / \mathrm{m}^{3} .
\end{aligned}
$$

Cylindrical shell

$$
a=b=0.20 \mathrm{~m}, \quad R_{x} / a=\infty, \quad R_{y} / a=5, \quad R_{x y}=\infty .
$$

Spherical shell

$$
a=b=0.20 \mathrm{~m}, \quad R_{x} / a=R_{y} / a=5, \quad R_{x y}=\infty .
$$

Impactor (spherical) properties

$$
\begin{aligned}
E_{i} & =210 \mathrm{GPa}, \text { diameter }=1.27 \mathrm{~cm}, \quad v_{i}=0.30, \\
\rho_{i} & =7800 \mathrm{~kg} / \mathrm{m}^{3}, \quad v_{0}=3 \mathrm{~m} / \mathrm{s} .
\end{aligned}
$$

\subsection{Effect of core thickness}

The impact response of clamped free composite sandwich cylindrical shells with different core thicknesses is studied and is depicted in figures 5-8. The face sheets are made of graphite/epoxy material ( $1 \mathrm{~mm}$ thick) with core (case I) of variable thickness (e.g., 0, 5, 10 and $15 \mathrm{~mm}$ ). From figures $5-8$ it is observed that due to the increase in core thickness, the contact force increases, as there is an increase in structural stiffness. It is also to be noted that the number of impact events decreases due to the increase of structural stiffness. Impactor displacement and target point displacement response are also affected. It is further observed that the increase of core thickness results in the decrease of the magnitude of transient displacement. The impactor displacement also increases due to increase in structural stiffness. This is because of the fact that, in the case of a stiffer structure, the energy transfer from the impactor to the target structure is smaller compared to a less stiff structure. 

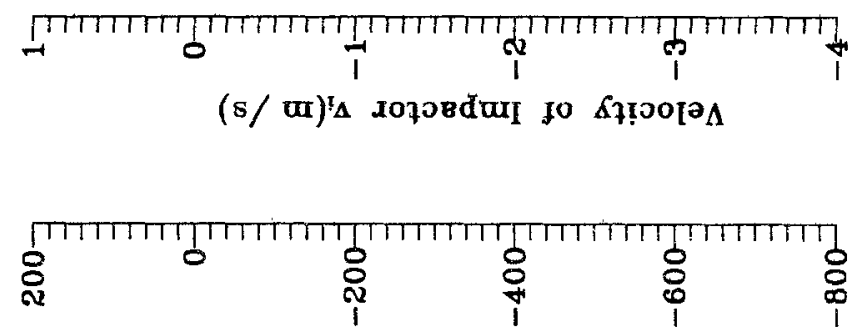

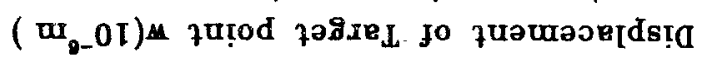

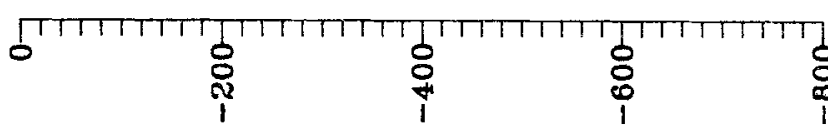

$\left(\mathrm{m}_{0-} \mathrm{OI}\right)^{\mathrm{r}_{M}}$ jopoeduI fo fuawaorjdsta

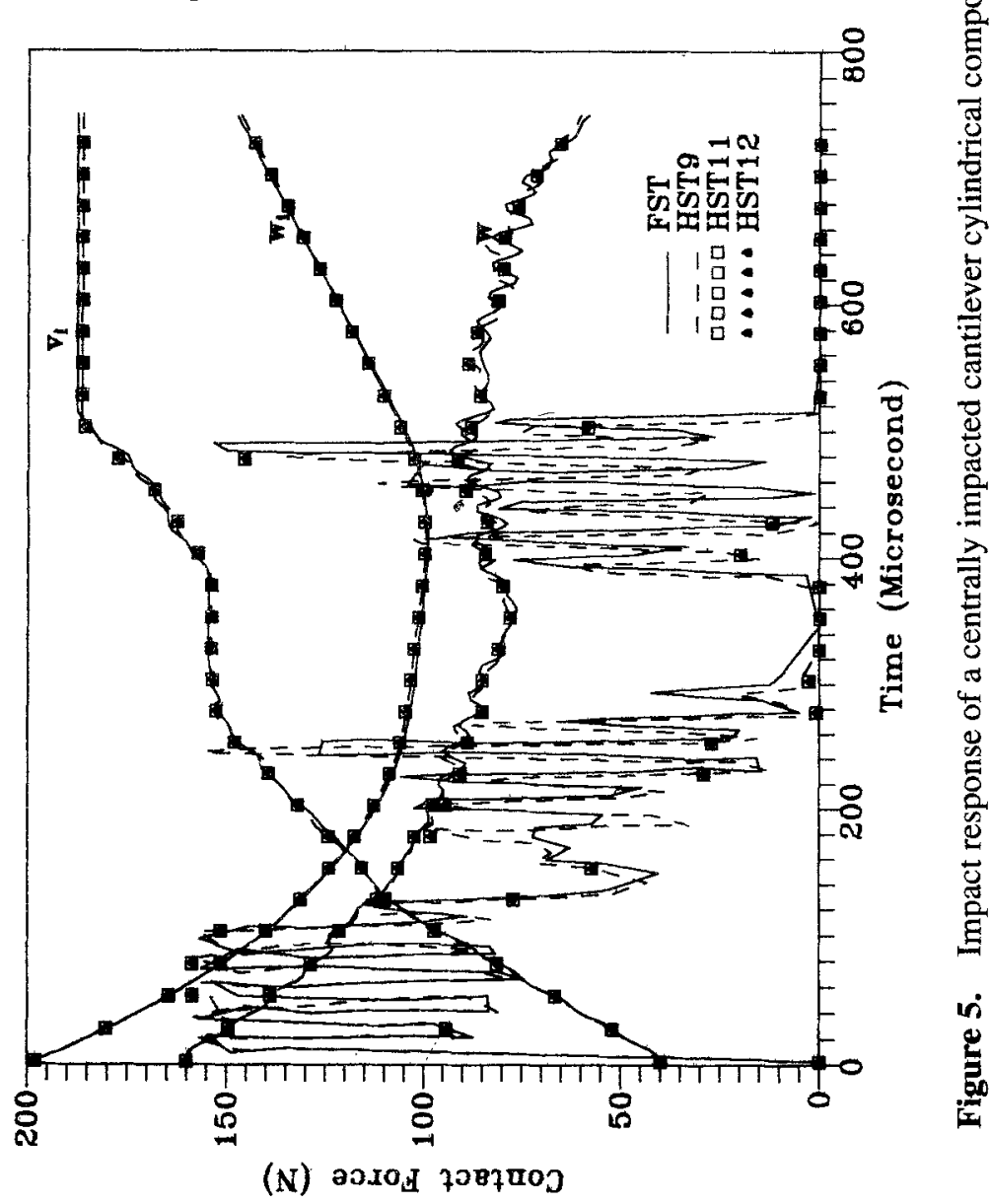



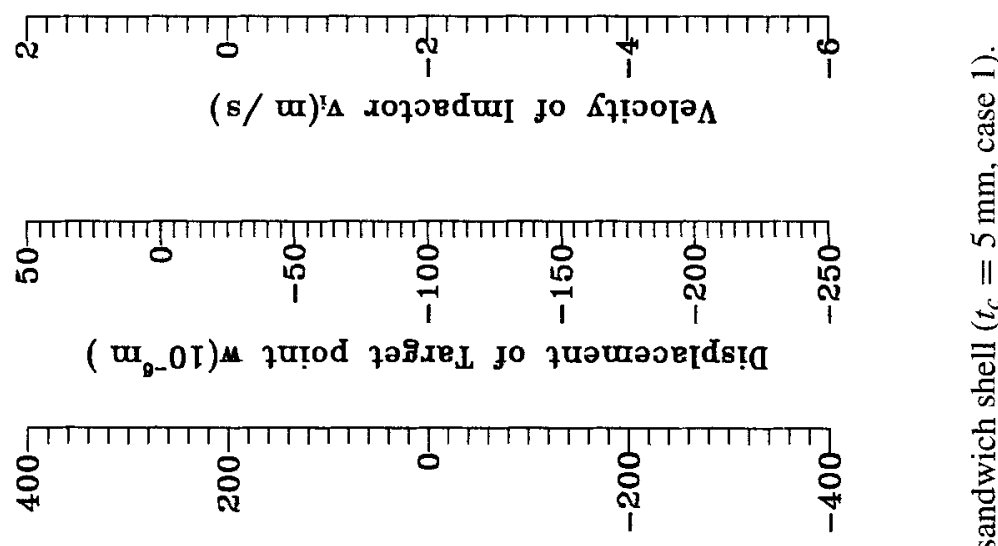

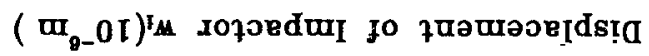

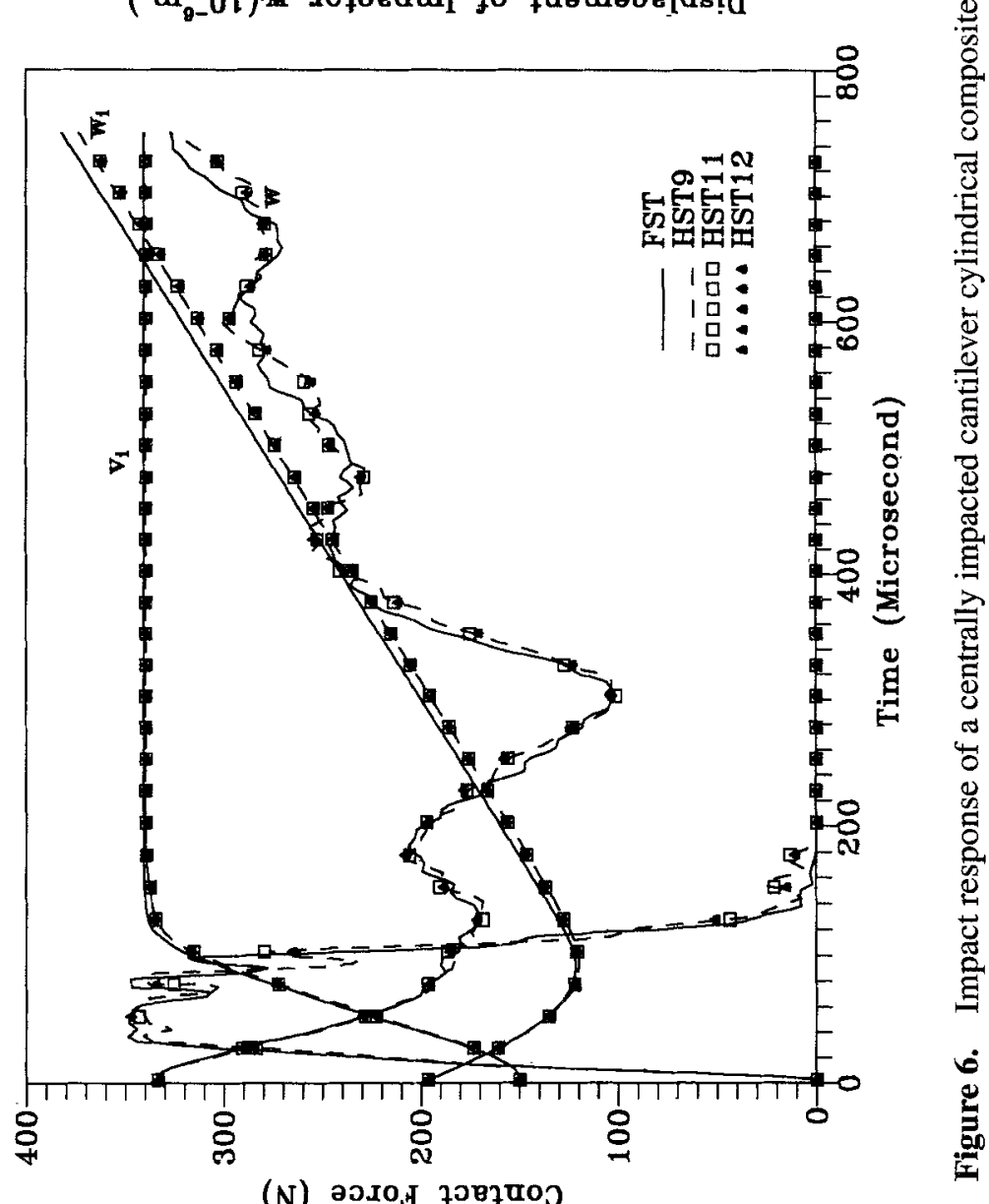

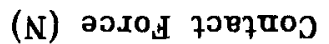



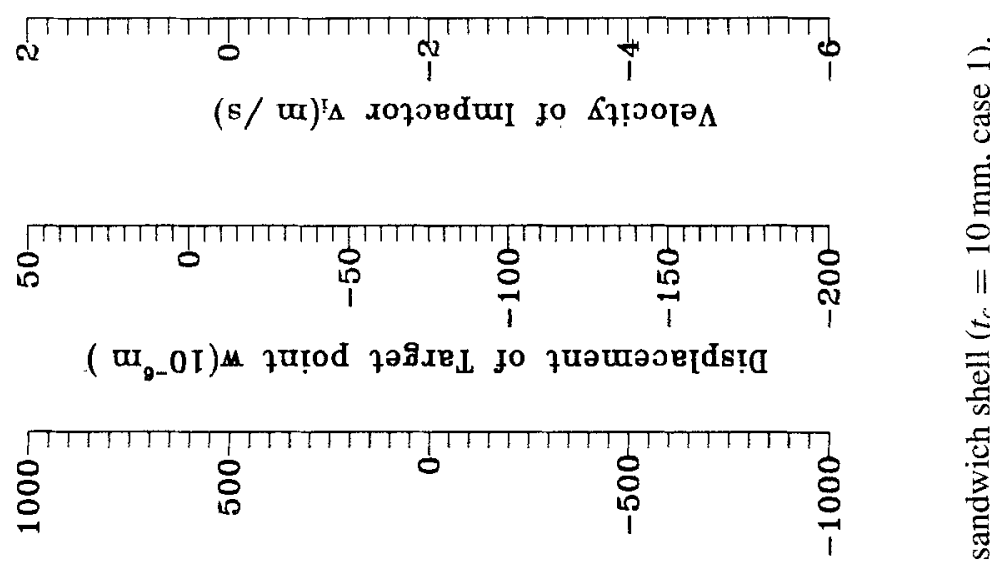

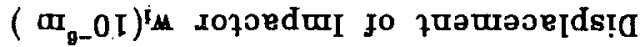

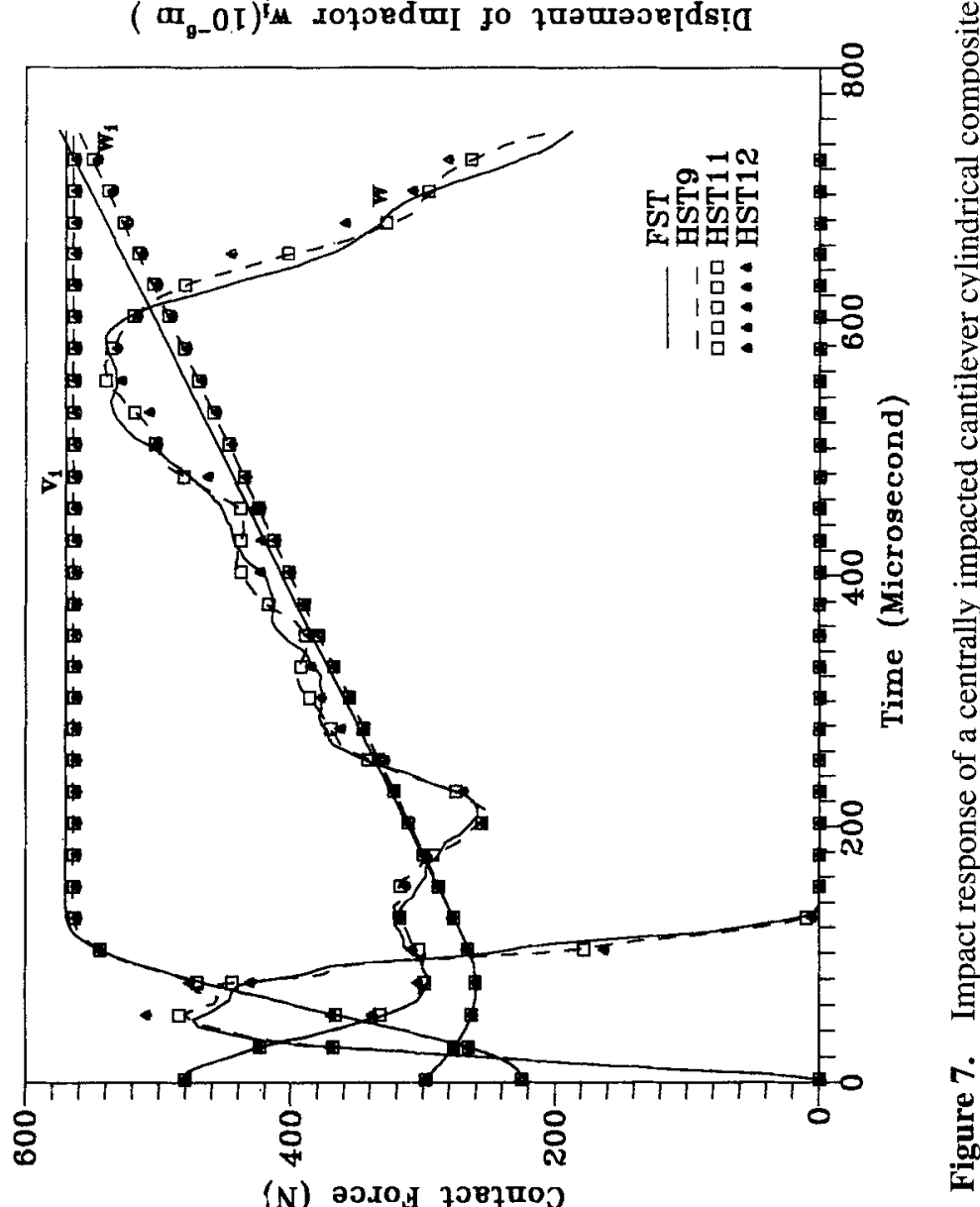

(N) ә0.0Н 7087ष0ว 

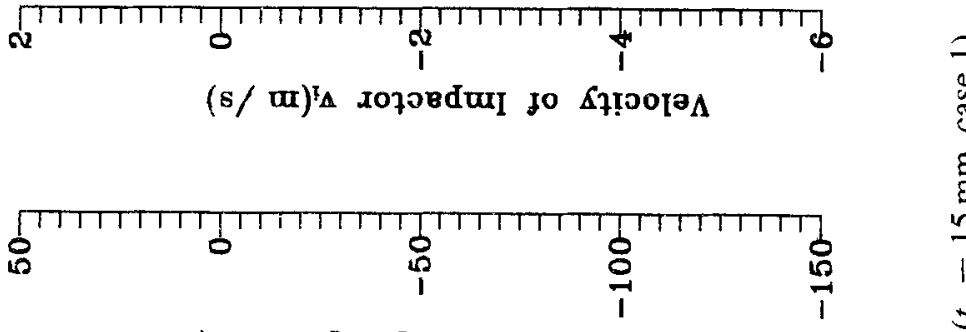

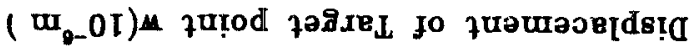

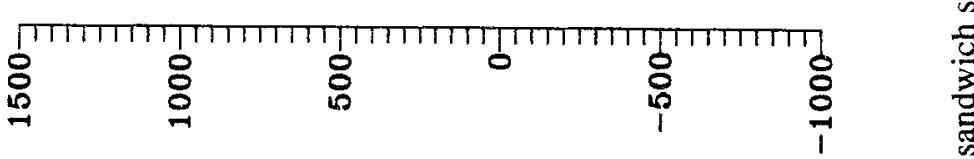

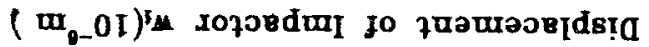

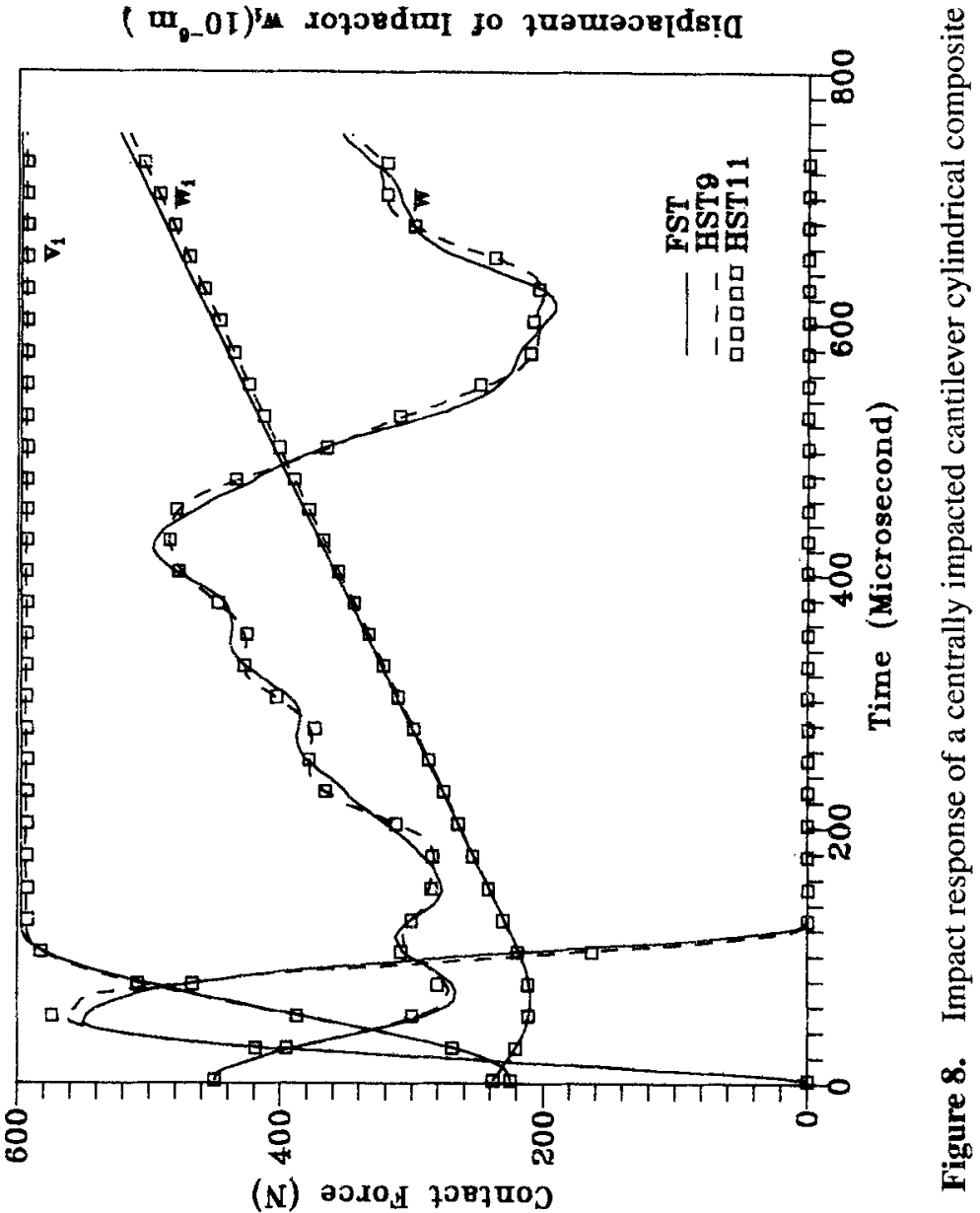

(N) องxо วอвวบัว 


\subsection{Effect of radius to span ratio}

The impact response of laminated shell sandwich structures (e.g., cylindrical and spherical shells) with different $R_{x} / a$ and $R_{y} / a$ ratios is studied next. The results reduce to those for a sandwich plate, when $R_{x}=R_{y}=\infty$. For cantilever cylindrical and spherical sandwich shells of $1 \mathrm{~mm}$ face thickness and $10 \mathrm{~mm}$ core thickness, the impact response is shown in figures 7 and 9 . It is observed that the patterns of behaviour for different $R / a$ ratios are more or less similar. This trend was also reported by Maiti \& Sinha (1995) and it can be explained in the following manner. The point impact is a localised phenomenon upto a certain initial time period and this time period decreases with the increase in structural stiffness. After this initial time period, the whole structure starts experiencing the disturbance, although the impact is limited to a point, and the form (plate or shell) of the target structure dominates in influencing the response.

\subsection{Effects of core materials}

The impact response of the target structure is also studied with different core materials (cases 2 and 3 ). The faces are of $1 \mathrm{~mm}$ thick graphite/epoxy composites and the cores are of $10 \mathrm{~mm}$ thick honeycombs or rigid foams. The target structure is a clamped free doubly curved spherical shell. The variation of contact force $(F)$, impactor displacement response $\left(w_{i}\right)$, target point displacement response $(w)$ and velocity profile $\left(v_{i}\right)$ of impactor are shown in figures 9-12 for different core materials. It is observed that for a very weak core (Case 2(3)), the contact force is minimum but the contact duration is almost equal. Further, the higher-order shear deformation theories provide higher contact force. The displacement and velocity profile of the impactor are also compared for different core materials, and it is to be noted that the displacement of impactor $\left(w_{i}\right)$ and velocity profile $\left(v_{i}\right)$ increase due to the increase of core stiffness. Incidentally, all shear deformation theories yield similar results for the displacement and velocity profile of the impactor, but variation is observed for the target point displacement response and is minimum for comparatively high shear modulus.

\section{Conclusion}

In the present investigation, the impact response of laminated sandwich shells is carried out using finite element analysis based on the higher-order and conventional first-order shear deformation theories. Computer programs are coded with the help of Fortran-77 language. The nine-noded Lagrangian isoparametric elements are used to discretise the analysis domain. The bending results of a sandwich composite plate compare well with those of the exact solution of Pagano (1970). The free vibration results are also found to agree well with those of Khatua \& Cheung (1973) and Raville \& Ueng (1967). The variation of contact force, displacement of impactor, displacement of target point and velocity profile of impactor are comparable with those of Goldsmith (1960). From the analysis of numerical results, it is observed that the contact force increases whereas the target point displacement response decreases due to the increase of core depth, as there is an increase in structural stiffness. The impact behaviour is also studied for different target 

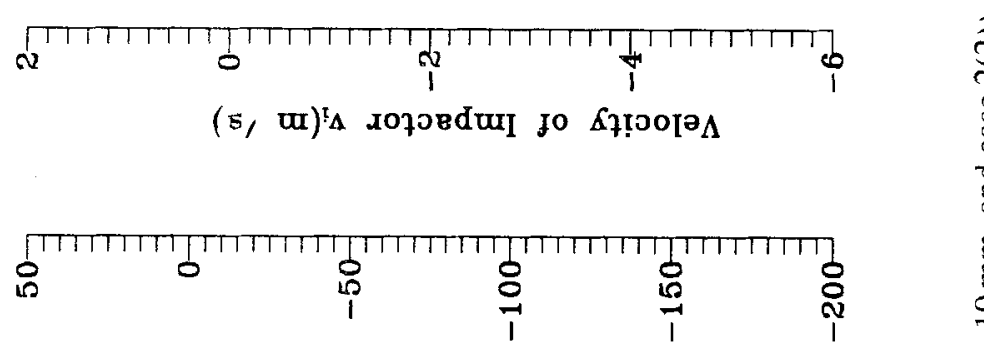

( 世
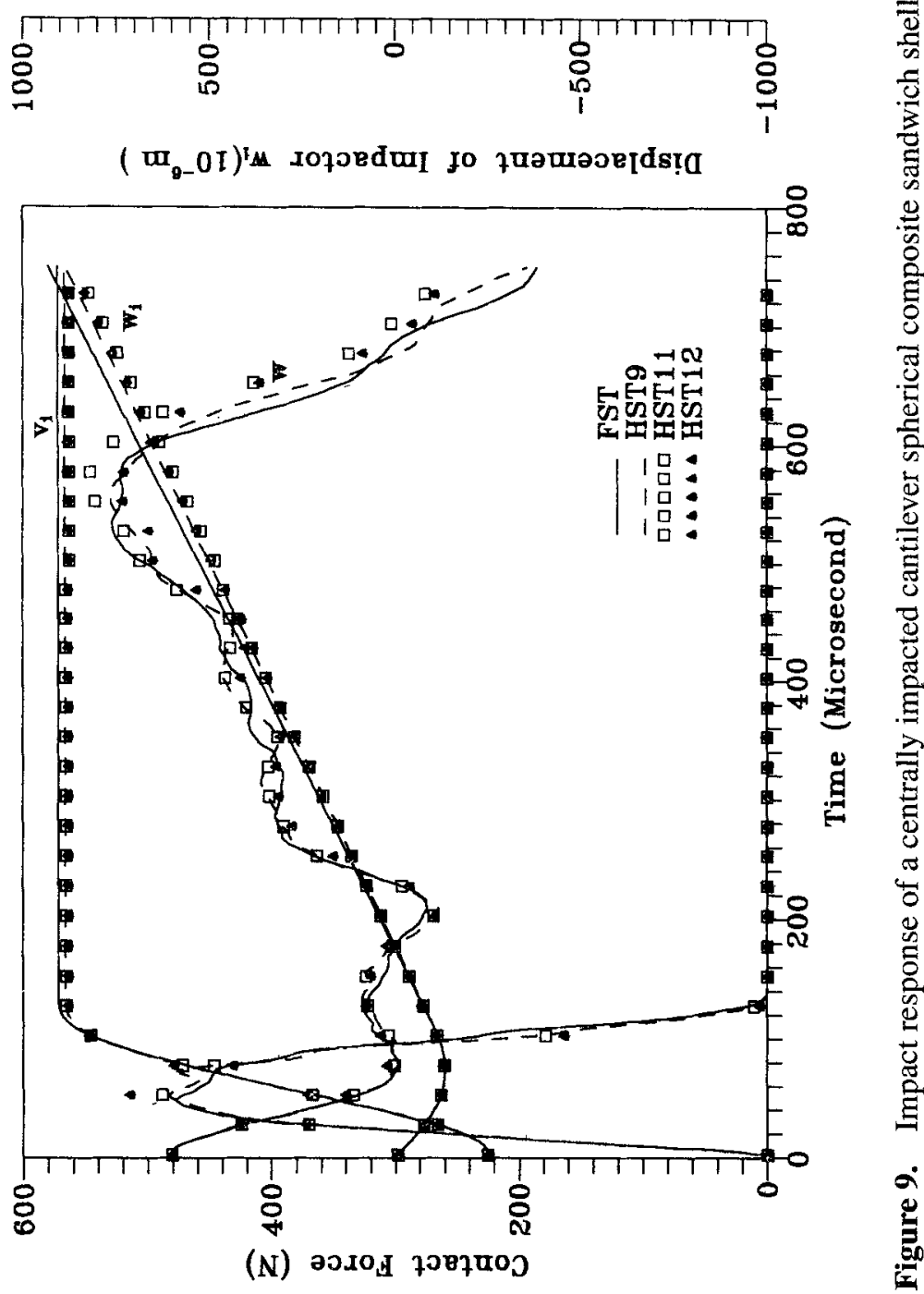


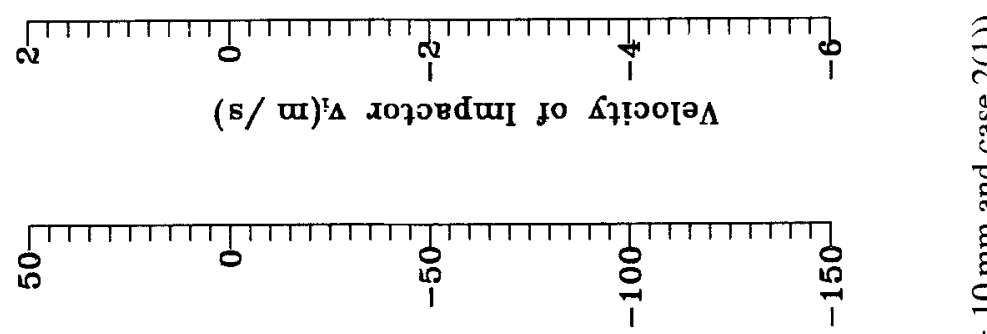

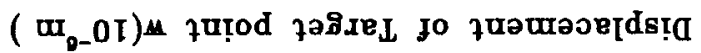

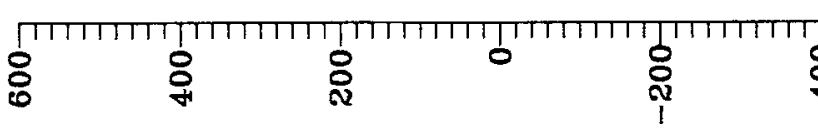

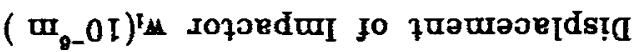

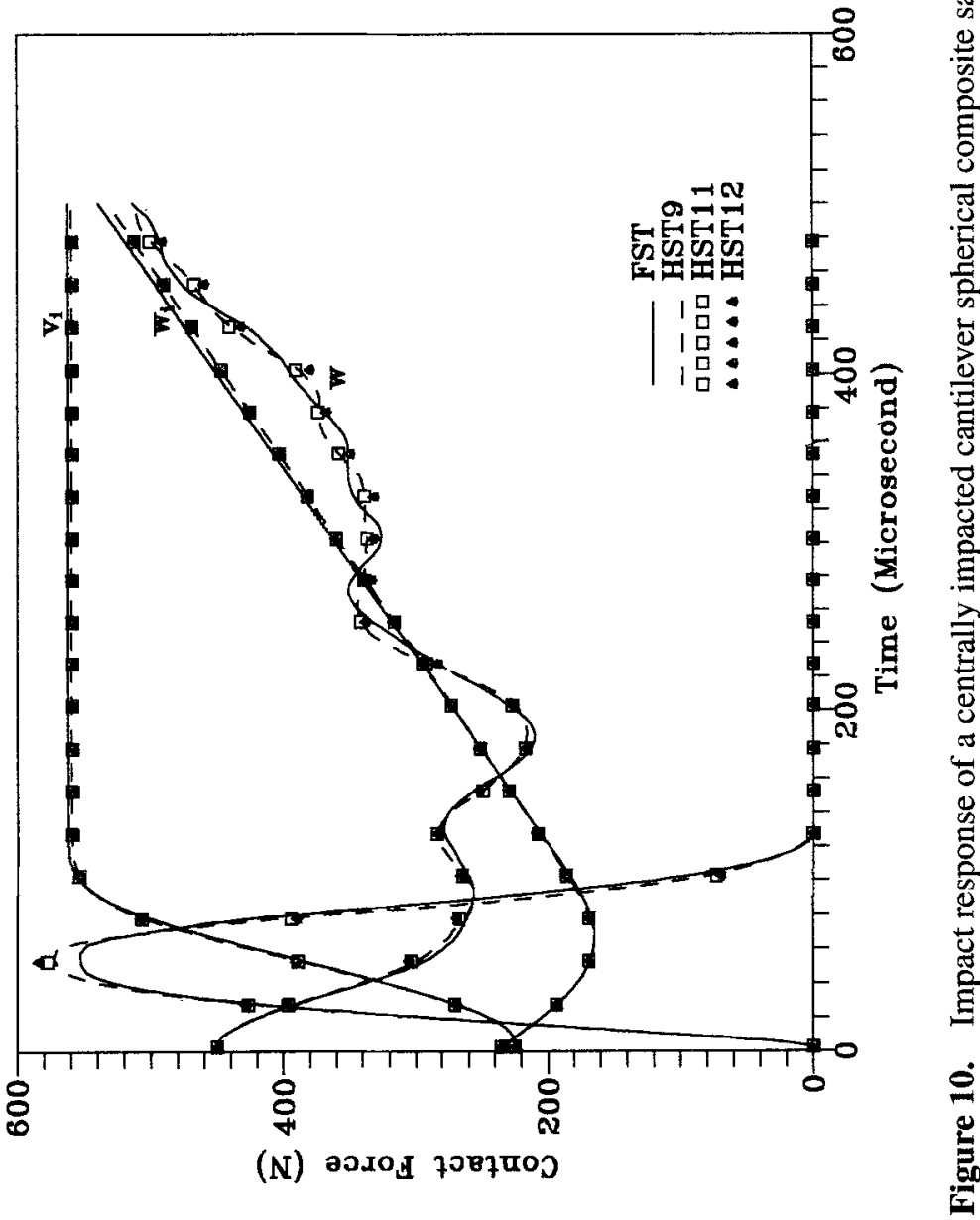




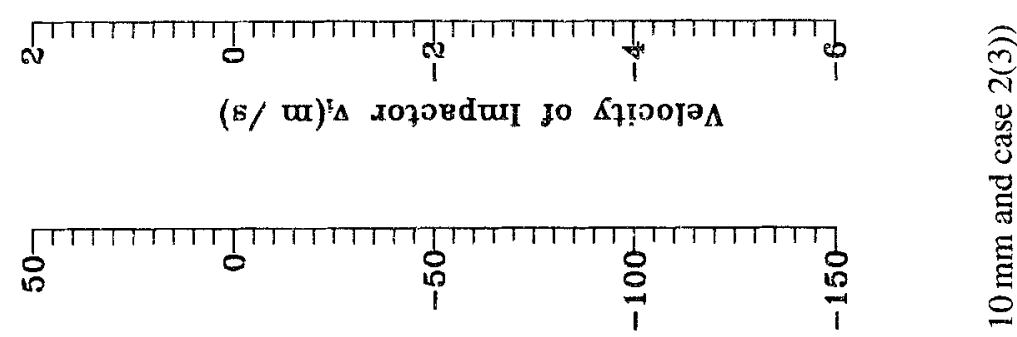

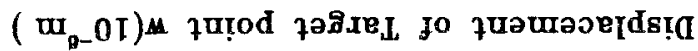

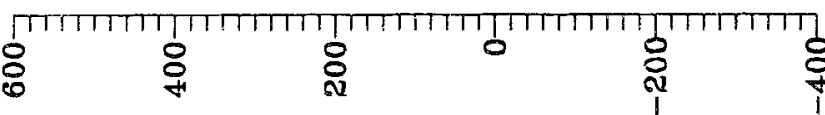
$\left(\mathrm{uI}_{\mathrm{g}-\mathrm{O}} \mathrm{OI}\right)^{\mathrm{r}_{\text {M }}}$ IopoeduI fo fuawaoe[ds!

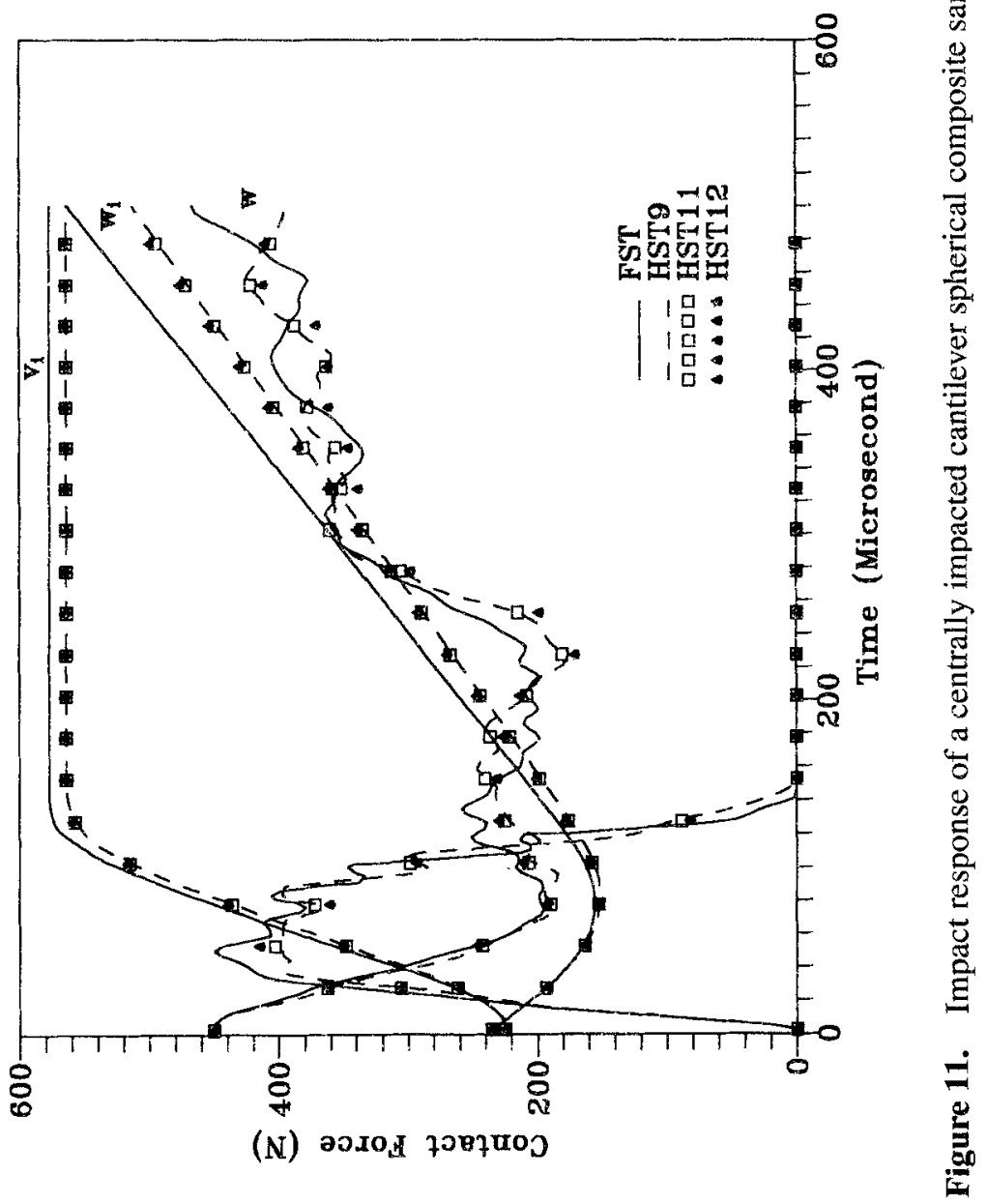




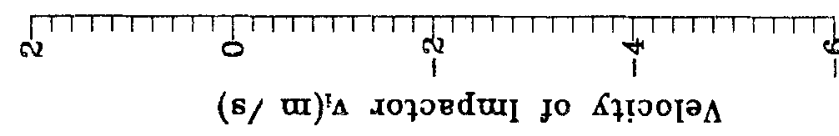

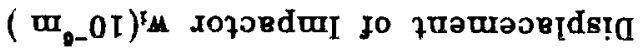

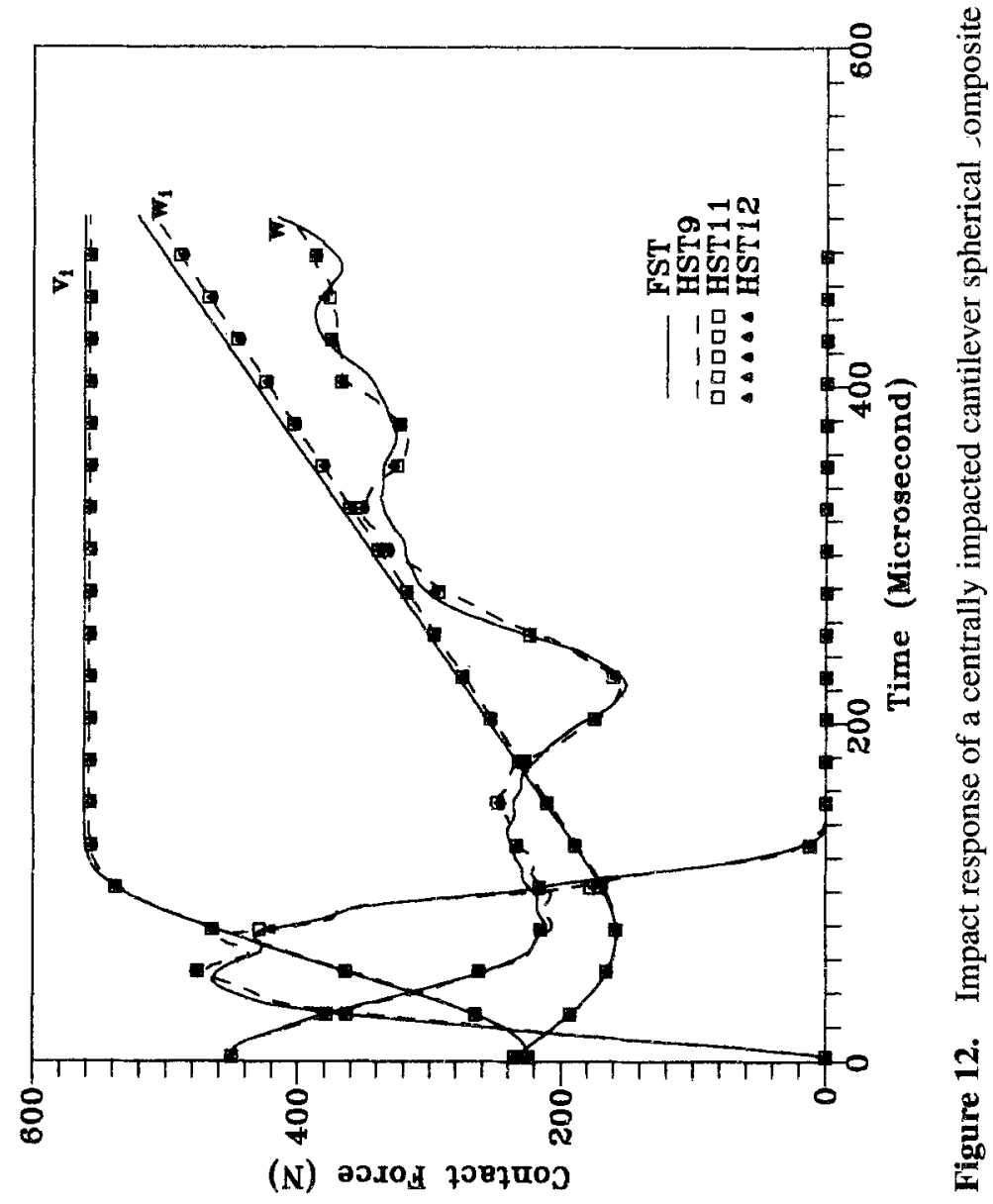


structures (plate, cylindrical and spherical shells) and it is shown that point impact is a localised phenomenon upto a certain time period, after which the whole structure starts experiencing the disturbance. From the analysis of impact behaviour of target structures of different core materials, it is noted that the contact force is minimum but the contact duration is almost equal for a very weak core (case 2(3)). Also, it is to be remarked that not many differences between FST and various HST results are observed in the present analysis. However, this may not be the case where the local indentation is enhanced due to the localised transverse deformation of the core.

\section{List of symbols}

$\begin{array}{ll}a, b & \text { planform dimension of the shell; } \\ {[B]} & \text { strain-displacement matrix; } \\ {[D]} & \text { rigidity matrix; } \\ E_{11 f}, E_{22 f}, \text { etc. } & \text { modulus of elasticity of face material; } \\ E_{11 c}, E_{22 c}, \text { etc. } & \text { modulus of elasticity of core material; } \\ E_{i} & \text { modulus of elasticity of impactor; } \\ \{F\} & \text { force vector; } \\ F_{c} & \text { contact force; } \\ F_{m} & \text { maximum contact force; } \\ {\left[K_{e}\right],[K]} & \text { element and global stiffness matrices; } \\ L_{e} & \text { Lagrange energy function; } \\ m_{i} & \text { impactor mass; } \\ {\left[M_{e}\right],[M]} & \text { element and global mass matrix; } \\ n & \text { contact stiffness; } \\ N_{i} & \text { shape function of node } i ; \\ R_{i} & \text { radius of impactor; } \\ R_{s} & \text { radius of target structure; } \\ t_{f} & \text { thickness of face sheet; } \\ t_{c} & \text { thickness of core ; } \\ u, v, w & \text { displacements along } x, y, z \text { directions respectively; } \\ u_{0}, v_{0}, w_{0}, \text { etc. } & \text { degrees of freedom; } \\ \left\{u_{e}\right\},\{u\} & \text { element and global displacement vector; } \\ \{\ddot{u}\},\{\ddot{u}\} & \text { element and global acceleration vector; } \\ v_{0} & \text { initial velocity of impactor; } \\ \ddot{w}_{i} & \text { acceleration of impactor; } \\ \alpha & \text { relative indentation; } \\ \alpha_{0} & \text { permanent indentation; } \\ & \end{array}$




$\begin{array}{ll}\alpha_{m} & \text { maximum relative indentation; } \\ \alpha_{c r} & \text { critical indentation; } \\ \rho & \text { mass density of the material; } \\ \xi, \eta & \text { natural coordinates; } \\ \epsilon_{x x}, \epsilon_{y y} \text { etc. } & \text { engineering strains; } \\ \epsilon_{x x}^{0}, \epsilon_{y y}^{0}, \epsilon_{z z}^{0} \text { etc. } & \text { generalised strains. }\end{array}$

Appendix A. Generalised strain-displacement relations

$$
\begin{aligned}
& \left\{\begin{array}{c}
\epsilon_{x x}^{0} \\
\epsilon_{y y}^{0} \\
\epsilon_{z z}^{0} \\
\gamma_{x y}^{0} \\
\gamma_{y z}^{0} \\
\gamma_{x z}^{0}
\end{array}\right\}=\left\{\begin{array}{c}
\partial u_{0} / \partial x+w_{0} / R_{x} \\
\partial v_{0} / \partial y+w_{0} / R_{y} \\
\theta_{z} \\
\partial u_{0} / \partial y+\partial v_{0} / \partial x+w_{0} / R_{x y} \\
\theta_{y}+\partial w_{0} / \partial y \\
\theta_{x}+\partial w_{0} / \partial x
\end{array}\right\} \\
& \left\{\begin{array}{c}
k_{x x} \\
k_{y y} \\
k_{z z} \\
k_{x y} \\
k_{y z} \\
k_{x z}
\end{array}\right\}=\left\{\begin{array}{c}
\partial \theta_{x} / \partial x+\theta_{z} / R_{x} \\
\partial \theta_{y} / \partial y+\theta_{z} / R_{y} \\
2 \bar{w}_{0} \\
\partial \theta_{x} / \partial y+\partial \theta_{y} / \partial x+\theta_{z} / R_{x y} \\
2 \bar{v}_{0}+\partial \theta_{z} / \partial y \\
2 \bar{u}_{0}+\partial \theta_{z} / \partial x
\end{array}\right\} \\
& \left\{\begin{array}{c}
\bar{\epsilon}_{x x}^{0} \\
\bar{\epsilon}_{y y}^{0} \\
\bar{\epsilon}_{z z}^{0} \\
\bar{\gamma}_{x y}^{0} \\
\bar{\gamma}_{y z}^{0} \\
\bar{\gamma}_{x z}^{0}
\end{array}\right\}=\left\{\begin{array}{c}
\partial \bar{u}_{0} / \partial x+\bar{w}_{0} / R_{x} \\
\partial \bar{v}_{0} / \partial y+\bar{w}_{0} / R_{y} \\
3 \bar{\theta}_{z} \\
\partial \bar{u}_{0} / \partial y+\partial \bar{v}_{0} / \partial x+\bar{w}_{0} / R_{x y} \\
3 \bar{\theta}_{y}+\partial \bar{w}_{0} / \partial y \\
3 \bar{\theta}_{x}+\partial \bar{w}_{0} / \partial x
\end{array}\right\} \\
& \left\{\begin{array}{c}
\bar{k}_{x x} \\
\bar{k}_{y y} \\
\bar{k}_{x y} \\
\bar{k}_{y z} \\
\bar{k}_{x z}
\end{array}\right\}=\left\{\begin{array}{c}
\partial \bar{\theta}_{x} / \partial x+\bar{\theta}_{z} / R_{x} \\
\partial \bar{\theta}_{y} / \partial y+1 \bar{\theta}_{z} / R_{y} \\
\partial \bar{\theta}_{x} / \partial y+\partial \bar{\theta}_{y} / \partial x+\bar{\theta}_{z} / R_{x y} \\
\partial \bar{\theta}_{z} / \partial y \\
\partial \bar{\theta}_{z} / \partial x
\end{array}\right\} .
\end{aligned}
$$




\section{Appendix B. Strain displacement matrix [B]}

$$
[B]_{23 \times 12}=\left[\begin{array}{ll}
{\left[B_{11}\right]_{12 \times 6}} & {\left[B_{12}\right]_{12 \times 6}} \\
{\left[B_{21}\right]_{11 \times 6}} & {\left[B_{22}\right]_{11 \times 6}}
\end{array}\right] \text {, }
$$

where

$$
\left[B_{11}\right]=\left[\begin{array}{cccccc}
N_{i, x} & 0 & N_{i} / R_{x} & 0 & 0 & 0 \\
0 & N_{i, y} & N_{i} / R_{y} & 0 & 0 & 0 \\
0 & 0 & 0 & 0 & 0 & N_{i} \\
N_{i, y} & N_{i, x} & N_{i} / R_{x y} & 0 & 0 & 0 \\
0 & 0 & 0 & N_{i, x} & 0 & N_{i} / R_{x} \\
0 & 0 & 0 & 0 & N_{i, y} & N_{i} / R_{y} \\
0 & 0 & 0 & 0 & 0 & 0 \\
0 & 0 & 0 & N_{i, y} & N_{i, x} & N_{i} / R_{x y} \\
0 & 0 & 0 & 0 & 0 & 0 \\
0 & 0 & 0 & 0 & 0 & 0 \\
0 & 0 & 0 & 0 & 0 & 0 \\
0 & 0 & 0 & 0 & 0 & 0 \\
0 & 0 & 0 & 0 & 0 & 0 \\
0 & 0 & 0 & 0 & 0 & 0 \\
0 & 0 & 0 & 0 & 0 & 0 \\
0 & 0 & 0 & 0 & 0 & 0 \\
0 & 0 & 0 & 0 & 0 & 0 \\
0 & 0 & 0 & 0 & 0 & 0 \\
0 & 0 & 2 N_{i} & 0 & 0 & 0 \\
0 & 0 & 0 & 0 & 0 & 0 \\
N_{i, x} & 0 & N_{i} / R_{x} & 0 & 0 & 0 \\
0 & N_{i, y} & N_{i} / R_{y} & 0 & 0 & 0 \\
0 & 0 & 0 & 0 & 0 & 3 N_{i} \\
N_{i, y} & N_{i, x} & N_{i} / R_{x y} & 0 & 0 & 0
\end{array}\right],
$$




$$
\left[B_{22}\right]=\left[\begin{array}{cccccc}
0 & 0 & 0 & N_{i, x} & 0 & N_{i} / R_{x} \\
0 & 0 & 0 & 0 & N_{i, y} & N_{i} / R_{y} \\
0 & 0 & 0 & N_{i, y} & N_{i, x} & N_{i} / R_{x y} \\
0 & 0 & 0 & 0 & 0 & 0 \\
0 & 0 & 0 & 0 & 0 & 0 \\
0 & 2 N_{i} & 0 & 0 & 0 & 0 \\
2 N_{i} & 0 & 0 & 0 & 0 & 0 \\
0 & 0 & N_{i, y} & 0 & 3 N_{i} & 0 \\
0 & 0 & N_{i, x} & 3 N_{i} & 0 & 0 \\
0 & 0 & 0 & 0 & 0 & N_{i, y} \\
0 & 0 & 0 & 0 & 0 & N_{i, x}
\end{array}\right]
$$

with $i=1,2,3, \ldots 9$.

\section{References}

Bachrach W E, Hansen R S 1989 Mixed finite element method for composite cylinder subjected to impact. AIAA J. 27: 632-638

Cairns D S, Lagace P A 1989 Transient response of graphite/epoxy and kevlar/epoxy laminates subjected to impact. AIAA J. 27: 1590-1596

Christoforou A P, Swanson S R 1990 Analysis of simply supported orthotropic cylindrical shells subjected to lateral impact loads. J. Appl. Mech. 57: 376-382

Goldsmith W 1960 Impact: The theory and physical behavior of colliding solids (London: Edward Arnold)

Khatua T P, Cheung Y K 1973 Bending and vibration of multilayered sandwich beams and plates. Int. J. Numer. Methods Eng. 6: 11-24

Kim C-G, Jun E-J 1992 Impact resistance of composite laminated sandwich plates. J. Compos. Mater. 26: 2247-2261

Lin H J, Lee Y J 1990a Impact-induced fracture in laminated plates and shells. J. Compos. Mater. 24: $1179-1199$

Lin H J, Lee Y J 1990b Use of statical indentation laws in the impact analysis of composite laminated plates and shells. J. Appl. Mech. 57: 787-789

Maiti D K, Sinha P K 1994 Bending and free vibration analysis of shear deformable laminated composite beams by finite element method. Comput. Struct. 29: 421-431

Maiti D K, Sinha P K 1995a Impact behaviour of thick laminated composite beams. J. Reinforced Plastics Compos. 14: 255-279

Maiti D K, Sinha P K 1995b Bending, free vibration and impact response of thick laminated composite plates. Comput. Struct. (in press)

Maiti D K, Sinha P K 1995c Finite element impact analysis of doubly curved laminated composite shells. J. Reinforced Plastics Compos. (in press)

Nemes J A, Simmonds K E 1992 Low-velocity impact response of foam-core sandwich composites. J. Compos. Mater. 26: 500-519

Pagano N J 1970 Exact solutions for rectangular bidırectional composites and sandwich plates. J. Compos. Mater. 4: 20-34

Raville M E, Ueng C E S 1967 Determination of natural frequency of vibration of a sandwich plate. Exp. Mech. 490-493 
Sun C T, Chen J K 1985 On the impact of initially stressed composite laminates. J. Compos. Mater. 19: 490-504

Tan T M, Sun C T 1985 Use of statical indentation laws in the impact analysis of laminated composite plates. J. Appl. Mech. 52: 6-12

Wu H T, Springer G S 1988 Impact induced stress, strains and delamination in composite plates. J. Compos. Mater. 22: 533-560

Wu H T, Chang F 1989 Transient dynamic analysis of laminated composite plates subjected to transverse impact. Comput. Struct. 31: 453-466

Yang S H, Sun C T 1981 Indentation law for composite laminates. NASA CR-165460

Yang S H, Sun C T 1982 Indentation law for composite laminates. Composite materials: Testing and design, ASTM STP 787, pp 425-449 